\title{
Children dying in car trunks: how adequate are child death databases?
}

\author{
Patricia F Waller, Carmen M Eribes
}

\begin{abstract}
Objective-To determine the frequency of and circumstances surrounding child deaths resulting from inadvertent entrapment in motor vehicle trunks in the US by querying child fatality review databases. Method-A telephone survey was conducted with the persons or offices identified as having primary responsibility for child fatality review programs in each state. The survey requested information on the number of child deaths resulting from trunk entrapments, the ages of the victims, the time period covered by the surveillance system, and variables concerning the circumstances surrounding each incident.
\end{abstract}

Results-All states reported that these deaths are exceedingly rare, with most reporting no such events in recent history. However, state databases could not be readily accessed to identify such deaths. There was enormous interstate variation in guidelines governing the population covered by the child fatality review process. The age range varied greatly from one jurisdiction to another, and often only children in the state's welfare system were included. Interstate differences in practices preclude meaningful compilation of data across jurisdictions.

Conclusions-It was not possible to ascertain the incidence of inadvertent entrapment of children in vehicle trunks because there is no consistency in the available databases. A national database of child fatalities, based on standardized guidelines and definitions, is needed to identify causes and magnitude of specific child deaths, in order to design, implement, and evaluate interventions.

(Injury Prevention 2000;6:171-174)

Keywords: child death databases; car trunk (boot); entrapment; hyperthermia; asphyxiation

Transportation Research Institute, University of Michigan P F Waller

School of Nursing, University of Michigan C M Eribes

Correspondence to: Dr P F Waller, 1779 Crawford Dairy Road, Chapel Hill, NC 27516, USA (email:

pwaller@umich.edu) becoming locked in a passenger vehicle trunk compartment. These stories led to inquiries concerning the frequency of such events and how they might be prevented. At least two of the major motor vehicle manufacturers announced new technologies for enabling occupants of car trunks to escape.

A recent report from the Centers for Disease Control identified 11 trunk entrapment deaths that occurred during the summer of 1998, in three separate events. The report described an additional eight deaths in six events occurring between 1987 and 1995. The author concluded that the identified deaths "probably represent a minimum number of such deaths". ${ }^{1}$

The primary purpose of this project was to survey each of the states to determine the frequency of car trunk entrapments of children, and, when they occur, the circumstances surrounding them. However, the interview findings also evolved into an evaluation of child death databases.

\section{Method}

To obtain information on the frequency of child deaths resulting from vehicle trunk entrapment, we sought to contact, in each state, key agencies having responsibility for monitoring such deaths. Two major sources provided the information used for our initial inquiries. First, the State and Territorial Injury Prevention Directors' Association (STIPDA) included us in a national conference call that led to feedback from a number of states, as well as providing leads to key persons to contact in some states. Second, the Centers for Disease Control put us in contact with the National Center on Child Fatality Review, an organization in California that is attempting to track child deaths. This organization provided us with a copy of a directory they are preparing entitled, International Contacts for Multi-Agency Child Death Review Activities. This directory included the names and addresses of key contacts in each of the states and territories.

Based on the information provided by these sources, contacts were made with every state and the District of Columbia, as well as several territories. In virtually every instance, the original contact was not able to provide the requested information but rather provided other contacts that were subsequently pursued. The key information sought is listed in box 1.

Contacts were made by telephone, email, and fax, and interviews were conducted by the authors, primarily Dr Eribes. Every effort was made to determine the ages of children, other parameters of the population, and the time frame.

\section{Results}

(1) In almost no case was the requested information available from the initial contact.

(2) There is no readily available source of this kind of information.

(3) There is considerable variation in how states and jurisdictions define "child". Some 


\section{Box 1: Information sought from states} and territories

1. The name, title, and affiliation of the person providing the information.

2. Telephone, fax, and email address of the person providing the information.

3. The jurisdiction covered by the information provided.

4. Age range of children covered by the agency's surveillance.

5. Other parameters defining the population of children covered.

6. Number of vehicle trunk entrapment events.

7. Number of victims involved in each.

8. Time period covered by the information provided.

9. Information for follow up inquiry.

For each fatal trunk entrapment event identified:

1. Where did the event happen? (State/territory)

2. What is (are) the age(s) of the child(ren) in each event?

3. What is the sex of the child(ren) in each event?

4. What was the time of day each event occurred?

5. What day of the week did each event occur?

6. What month of the year did each event occur?

7. In what year did the event occur?

8. In what state or jurisdiction did each event occur?

9. What was the make and model of the vehicle involved?

10. What was the location of the occurrence? (Home/school/friend's house/etc).

11. How far away from home did the event take place?

12. What led to the subsequent opening of the trunk?

13. What was the cause of death? (Lack of oxygen/ heat/cold).

14. Was there more than one child involved in the event? If so, how many?

review only child deaths occurring to victims 5 and under. Others include up to 12 or 14 , or through 17 or 18 .

(4) There is also considerable variation in the population covered. Some states include all children within the specified age ranges. However, quite a few include only children covered by social services, and still others would include these cases only if there were suspicion of child abuse. Still others would not include the case if it were considered deliberate. (These latter would be handled by the criminal justice system.)

(5) Some states review only a sample of eligible cases, but no information was provided on how the sample is selected. Presumably the reviewed cases are representative of all cases. However, for events that are rare, a sampling system may be inadequate.

(6) In many states there is no compilation of data at the state level. Rather, data are compiled and reviewed at the county or city level. Some counties send information to the state while others do not. Furthermore, local jurisdictions use their own criteria for reporting, for example, age.

(7) Many states have no authority to compel local jurisdictions to provide detailed information on child deaths, and even when such authority exists, local officials do not always comply. Consequently, even when a system is presumably in place, it frequently fails to achieve its purpose. Local jurisdictions choose whether or not to report, and if they report, they determine the types of cases reported, as well as how much and what kind of data they report.

(8) All states maintain vital statistics. However, cause of death is usually based on the International Classification of Disease, ninth revision (ICD-9) codes. ${ }^{2}$ These codes do not include death from entrapment in car trunks. Rather, such cases would be classified as suffocation, asphyxiation, hyperthermia, or hypothermia, and the fact that a motor vehicle was involved may not be identified. In ICD-9, motor vehicle deaths include those that result from some kind of collision, as well as deaths resulting from exhaust gas (E818, E868.2). Other ICD-9 codes include death by suffocation due to lack of air (in a closed place) (E913.2), hyperthermia (992), and accidental hypothermia (991.6), but the latter two conditions do not include $\mathrm{E}$ codes that identify the factors contributing to the condition. Even when $\mathrm{E}$ codes are applicable, they do not differentiate sufficiently to identify deaths from trunk entrapment. Consequently, these data cannot be used to identify the type of death of concern here. ICD-10 codes also make no provision for this type of death.

(9) There is considerable variation in the timeliness with which cases are reviewed. In one state in which it was known that such an event occurred in 1998, those responsible for monitoring child deaths had no information on it, because they receive cases only in the year after an event.

(10) Persons contacted who had been in their positions for a number of years usually relied on their memory. Without exception, they felt that such an occurrence would be so atypical that it would be recalled. A contact in one state knew of such a case in 1988 and tracked it down.

(11) States varied in how willing they were to provide information on specific occurrences, for example, reporting only information that had already appeared in the press.

(12) Press clippings appear to be a much more effective source of information on these deaths than do official records systems. The report from the Centers for Disease Control, based on a NEXIS-LEXIS search of newspapers, magazines, wire services, and broadcast transcripts, uncovered many more incidents than our survey of agencies responsible for surveillance of these fatalities. However, even this approach identified only 12 deaths over a period of 12 years. $^{3}$

(13) The children who are victims of this type of occurrence are usually between the ages of 2 and 6. Whether older children also experience entrapment but are able to escape, and hence do not become a part of a fatality database, could not be determined from this survey.

(14) Several respondents reacted negatively to the inquiry about trunk entrapment deaths of children, expressing dismay that so much attention was being given to such a rare event 
when other factors are responsible for many more child fatalities.

(15) Ten cases were reported by the survey, with all but one occurring in 1998. However, for one state that had no information on any such cases, at least two were reported in press clippings.

\section{Discussion}

Child fatalities have received special attention in recent years, and recommendations have been made for their review and monitoring. Of particular note are those by Durfee ${ }^{4}$ and Kaplan, ${ }^{5}$ included in a report on child fatality review teams sponsored by the Office of Juvenile Justice and Delinquency Prevention, US Department of Justice. ${ }^{6}$ However, the primary focus of this effort was on child abuse and neglect and did not necessarily cover the circumstances that might lead to inadvertent car trunk entrapment. A subsequent report from the ABA Center on Children and the Law compiled an annotated bibliography of resource materials for child fatality review teams, ${ }^{7}$ but again the emphasis is on children who, for one reason or another, are under the jurisdiction of welfare agencies or the courts. In the $\mathrm{ABA}$ study, inquiries to some of the jurisdictions presented as having exemplary systems failed to reveal any systematic review of the kinds of deaths focused on here. Moreover, the information provided by the persons identified as having primary responsibility for monitoring child deaths was far from complete. A number of factors contributed to this inadequacy.

First, information was not compiled in a way that would clearly identify this type of death. Based on ICD-9 coding, such deaths would likely be classified as hyperthermia, suffocation, or hypothermia, with no indication that a motor vehicle was involved.

Second, in many instances available information was far from timely.

Third, in many instances all children are not included under whatever surveillance system is in effect. For example, in one jurisdiction records are maintained for children under 5 years of age, except in the case of suicide where children under 14 are included. Children under 1 year of age are handled by those responsible for infant mortality. Child mortality review covers all children who are, or have been, under the welfare system within the previous 10 years, but is limited to deaths considered "accidental or suspicious". When all children are not included, most often coverage is limited to children under child protective services. Such variations in coverage preclude the compilation of deaths by cause across jurisdictions.

Fourth, even when the full range of children is considered, only a sample may be selected for consideration. As a result, relatively rare events, such as trunk entrapments of children, may be overlooked.

Fifth, in a number of states, records are maintained at the local level only. If data are submitted to the state, often they are described in ways that preclude identification of these cases, for example, the death may be listed as suffocation with no information on how suffocation occurred.

Sixth, the ages of children covered by the surveillance system varies from one jurisdiction to another.

In spite of the severe limitations of these information systems, it may be concluded that child deaths from vehicle trunk entrapments are rare. In many states the person reporting had been in place for many years and appeared to be knowledgeable about child deaths occurring from unnatural causes. Rarely were child deaths recalled that resulted from vehicle trunk entrapment, although in a few instances there were reports of child deaths occurring when children were left locked in an enclosed vehicle in high temperatures.

These deaths are not considered high priority by those responsible for child health and welfare because they apparently occur with such low frequency. However, because of the poor identification of these events, it is not possible to get a clear estimate of how often they occur. Nevertheless, because other causes of injury fatality are so much more frequent, it is not likely that public health officials would give high priority to trunk entrapment deaths.

When these events do occur, the victims are extremely young, so that any interventions requiring victim participation must be readily understood and readily usable by a young child. While technological interventions are usually preferable to educational ones, in the case of young children it may be more useful to ensure that parents consider checking the trunk when children are missing, and, even more important, that parents take care not to leave cars and car trunks open when young children are around.

It appears that child trunk entrapment fatalities are rare. However, in the absence of complete recording of child deaths, it is not possible to determine accurately the magnitude of this problem. Nevertheless, it may be possible to devise a technology to detect the presence of a breathing organism in the trunk and trigger an alarm. In addition, effort should be made to alert parents and other responsible adults to the danger of such occurrences, particularly in warm weather. The age of most victims makes it difficult to devise effective interventions that rely on their participation to be effective.

This study underscores the need for a valid child fatality database at both the state and federal levels. Despite widespread efforts to establish data systems that rapidly identify and monitor children's deaths and their causes, no jurisdiction was able to respond with certainty to this inquiry. Information in such a database should be available in a timely fashion and include extensive information on the circumstances surrounding each event. ${ }^{8}$ Likewise, the recent conference report from the Action on Injury Conference in London recommends "better surveillance systems...relevant to injury prevention issues". 9 
An excellent model is the Fatality Analysis Reporting System, a census of fatal traffic crashes in the US. It includes extensive information on the victim, the vehicle(s) involved, and environmental factors surrounding the event. ${ }^{10}$ This data source has enabled the identification of critical variables that contribute to risk of death in a traffic crash and has been the basis for designing and evaluating effective countermeasures.

Although the establishment of child fatality review teams is laudable, support is needed to enable these teams to maintain surveillance of all child deaths, not just those that may be related to child neglect or abuse. An effective child death database would include uniform standardized definitions and system-wide coordination, with sufficient resources and enforcement to ensure comprehensive coverage. While local data systems are important, a national database is needed to detect less frequent events that can nevertheless be prevented through effective countermeasures.
This study was supported in part by a grant from General Motors Inc.

1 Centers for Disease Control. Fatal car trunk entrapment involving children-United States, 1987-1998. MMWR Morb Mortal Wkly Rep 1998;47(47):1019-22.

2 International classification of diseases. Volumes 1 and 2. Clinical modification. 4th Ed; ICD.9.CM. (Report No DHHS (PHS) 91-1260.) Washington, DC: Health Care Financing Administration, 1991

3 Title 42, The Public Health and Welfare, $₫ 5106 a, 1997$.

4 Durfee M. Fatal child abuse: interventions and prevention. Child fatality review teams: a multi-agency approach. Washington, DC: US Department of Justice, 1994.

5 Kaplan SR. Child fatalities and child fatality review teams. Child fatality review teams: a multi-agency approach. WashChild fatality review teams: a multi-agency approac
ington, DC: US Department of Justice, 1994.

6 Child fatality review teams: a multi-agency approach. Washington, DC: US Department of Justice, 1994

7 Kaplan SR, Neill SE. Where to go for what you need to know. A selective annotated bibliography of resource materials for child fatality review teams. Washington, DC: $\mathrm{ABA}$ Center on fatality review teams. Washington,

8 Bonnie RJ, Fulco CE, Liverman CT, eds. Reducing the burden of injury —advancing prevention and treatment. Washington, DC: National Academy Press. 1999: 319.

9 Towner E, Hayes M. Action on injury; where do we go from here? Inj Prev 1998;4(Dec).

10 Traffic Safety Facts 1998. Washington, DC: National Highway Traffic Safety Administration, 1999: 208.

\section{Training in child passenger safety}

The International Center for Injury Prevention (ICIP) has announced its intention to open a National Child Safety Training Center in San Antonio, Texas in January 2001. The goal is to train technicians and instructors in child passenger safety. For information about ICIP visit their web site: www.cipsafe.org and to discuss training opportunities, email the executive director, Elaine Kizewski at: elaine@cipsafe.org.

\section{Mouth to mouth CPR?}

Survival after injury, or the reduction of sequelae, is often referred to as "tertiary prevention". In what has been described as a "landmark study", a team from the University of Washington have shown that "when performed by a bystander, cardiopulmonary resuscitation (CPR) with chest compression alone provides similar survival to standard CPR that involves mouth to mouth resuscitation. The criterion used in this randomized trial was survival to hospital discharge (Hallstrom et al, $N$ Engl f Med, 2000;342:1546-53).

\section{Envy, envy! A dog bite prevention trial}

Proving a point I tried to make in a previous editorial, more questions may be answered using a randomized controlled trial design. In a recent report in the $B M \mathcal{F}$, Simon Chapman (editor of our sister journal, Tobacco Control), and his colleagues, report on a randomized controlled trial to prevent dog bites in children. I was asked to review this and did so with mixed feelings because I would much preferred to have had the opportunity to publish this elegant, brief report of the trial evaluating the educational programme, "Prevent-a-Bite". This is an elegant study, simple but persuasive, and happily the results are positive: the programme appears to work (Chapman et al, BMF 2000;320:1512-13).

More envy! Head injuries among English cyclists

Another paper I reviewed for the BMF is one I would love to have published in Injury Prevention. It describes trends in serious head injuries among bicyclists in England and concludes, "Our findings, based on national data, suggest that cycle helmets are of substantial benefit to children, and contrary to popular belief, also to adults". The main finding is a significant decline in serious head injuries which "can only be attributed to increased helmet usage during the corresponding period". "The increase in non-head admissions seen here suggests that cycle usage was not falling".

Still more envy: funding for injury prevention centre

It was recently announced that the Alberta Centre for Injury Control and Research will receive $\$ 1.35$ million this year from the province's treasury. This is a substantial increase over the $\$ 600000$ received last year. The focus of the centre's work continues to be traffic, farming, suicide, falls, and injuries in the Aboriginal community. Congratulations to Louis Francescutti who spearheaded this initiative. Now, if only my own province were equally enlightened . . . 